\title{
RELAÇÕES INTERPESSOAIS E DE SABERES NA LINGUÍSTICA APLICADA: $O$ DESAFIO DA ALTERIDADE*
}

\section{INTERPERSONAL RELATIONSHIPS AND KNOWLEDGE IN APPLIED LINGUISTICS: THE CHALLENGE OF OTHERNESS}

Maria Marta Furlanetto ${ }^{* *}$

RESUMO: Neste trabalho, sob a perspectiva dialógica e discursiva, retomo a questão da subjetividade nos estudos da linguagem para situá-la na contemporaneidade, em que se articulam novos objetos e novos procedimentos que atuam como desafios para a Linguística Aplicada (LA) como campo transdisciplinar. Reflito sobre o desafio da alteridade, que implica a questão ética, e tento mostrar que, criando um espaço próprio e formas não estáveis de tratar cada prática em seu tempo, espaço e condição política dos sujeitos, a LA pode fazer-se e refazer-se sem limites. Nesta tarefa, exercitar o encontro com o outro em meio aos conflitos e contradições, em qualquer esfera, assume importância crucial.

PALAVRAS-CHAVE: Linguística aplicada. Subjetividade. Alteridade.

ABSTRACT: In this work, under the dialogical and discursive perspective, I retake the topic of subjectivity in language studies to situate it in contemporary times, in which new objects and new procedures articulate that act as challenges for Applied Linguisticas (LA) as transdisciplinary field. I reflect on the challenge of otherness, which implies the ethical issue, and I try to show that creating a space and not stable forms of treating each practice in his time, space and political condition of the subjects, the LA can make and remake himself without limits. In this task, exercising the encounter with each other amidst the conflicts and contradictions takes on crucial importance in any sphere.

KEYWORDS: Applied Linguistics. Subjectivity. Otherness.

\footnotetext{
Apresentado na mesa-redonda Linguística Aplicada e a produção do conhecimento na contemporaneidade, em 2011, no evento comemorativo dos 40 anos da Pós-graduação em Letras da UFSC.

${ }^{* *}$ Universidade do Sul de Santa Catarina (UNISUL), Campus Tubarão. Dra. em Linguística Aplicada. Professora no Programa de Pós-graduação em Ciências da Linguagem. Email: mmarta@intercorp.com.br
} 
[...] sempre precisamos de Foucault e de um ceticismo constante em relação a conceitos e modos de pensamento que nos são próximos.

(Alastair Pennycook, Uma linguistica aplicada transgressiva)

\section{INTRODUÇÃO}

Os desafios da Linguística Aplicada (LA), na contemporaneidade, remetem, a jusante, para sua rede de filiações a partir da área da Linguística, e a montante para um porvir que promete ter mil facetas, a levar em consideração por quem aí estiver engajado. Articulam-se novos objetos, novos procedimentos neste amplo campo das Ciências da Linguagem, hoje aberto à transdisciplinaridade, que chamamos Linguística Aplicada.

O desafio proposto/imposto pela alteridade diz respeito a todos nós, cabendonos refletir mais detidamente em algum aspecto do campo que ela abre para os linguistas e analistas que se dedicam às práticas atravessadas pelas inúmeras linguagens em seu labirinto, onde não poucas vezes constatamos nos perder, na tentativa de encontrar o caminho - caminho que só se legitima quando apreciamos resultados nessas práticas.

Ao aceitar a intrincação dos saberes e das subjetividades, escolhi perguntar como poderíamos ser bons mediadores de saberes relativamente às subjetividades em questão, seja nos espaços já cotidianamente ocupados - no magistério, nas relações profissionais (próximas, corporalizadas, ou distantes, quando a presença se corporifica mais fortemente pelo imaginário) -, seja nos contatos com práticas discursivas não cotidianas, nos ambientes em que a indisciplinaridade possa ser praticada.

Isso posto, vejo-me na injunção de retomar a questão da subjetividade, a partir de sua reconsideração (em todas as perspectivas adotadas) nos estudos da linguagem e das línguas, até chegarmos ao ponto de focalizá-la em sua contemporaneidade - em suas múltiplas facetas. Considero que, para além dos saberes e seus temas, e ainda assim conjugada a eles, a subjetividade em alteridade diz respeito a atitudes, e encarna a 
questão ética, ou seja, da responsabilidade pessoal de cada um relativamente aos outros - que não são nós mesmos mas estão em nós, tal como nos (re)lembrou Bakhtin em seu percurso filosófico. Por isso, optei inicialmente por retomar algumas considerações de Faraco (2001) ao nos propor desafios para o novo milênio.

\section{SUJEITO E SUJEITO - ALTERIDADE}

Faraco (2001, p.3) remete à seguinte constatação:

ao centrar seu foco de atenção na língua em si, a linguística não pode ter, ao mesmo tempo, o falante como um problema, o que a deixa permanentemente comprometida com uma determinada imagem cristalizada da pessoa humana.

Mesmo na Dialetologia e na Sociolinguística (pelo menos em sua abordagem inicial), comenta Faraco, não se vai além de "um ser genérico e quase abstrato", "um ente não problemático a respeito de quem pouco se precisa dizer" (2001, p.3). Não seria muito diferente nos trabalhos sobre interação face a face, interessando, aí, mais a dinâmica da conversação. Estamos no limiar das preocupações com a alteridade.

Faraco quer dizer que a análise de caráter predominantemente linguístico é conduzida de modo monológico", tomando o indivíduo ("singular e solitário") como princípio para a modelagem de teorias. A linhagem que contrasta com essa fundamentase na intersubjetividade como fator constituinte, pressupondo a impossibilidade de vivência humana sem o outro - e a relação com o simbolismo da linguagem. É claro que o desenvolvimento dessa percepção tem uma longa história:

A questão da intersubjetividade começa a tomar corpo [...] no início do século XIX, nos textos dos filósofos idealistas alemães. Trata-se de um momento particularmente interessante da história moderna em que os efeitos da revolução industrial começam a se fazer visíveis e o trabalho (o agir humano) vai-se tornando tema de reflexão filosófica sistemática. (FARACO, 2001, p.7)

Alteridade é a palavra-chave, hoje, para nós; a alteridade deriva os acontecimentos da vida (social) e é derivada deles, em espiral. Com o outro eu abre-se a linguagem para a proximidade, e também para o estranhamento; para a compreensão, e para a incompreensão; para a comunicação discursiva, e para o desentendimento e o equívoco. A espessura da linguagem, aberta pela alteridade, faz pensar no confronto do planejamento (um ideal) e das práticas (este é um ponto fundamental), em que os sujeitos se alinham e desalinham; faz pensar na concretude do mundo real: identidade e diferença absoluta, como expressa Faraco em seu texto.

Se, como assevera Ponzio (2008, p.233), a contribuição de Bakhtin à dialética materialista é ter explicitado que "o caráter fundamental da materialidade é a alteridade", estando implicado aí que o diálogo constitui a estrutura lógica do discurso, cabe explicitar que essa atitude filosófica traz em seu cerne uma indisciplinaridade de raiz: é a "crítica da categoria da identidade como categoria dominante hoje no pensamento e na práxis ocidental" (2008, p.234). Não é difícil entender que, apanhados

\footnotetext{
${ }^{1}$ Mas veja-se esta observação de Ponzio (2008: 245): “A palavra mais monológica não é mais do que o grau mais baixo de alusão à palavra do outro. [...] somente na interação dialógica, inserida em determinadas condições sociais, pode isolar-se, iludir-se em ser palavra a uma só voz."
} 
nessa malha, tenhamos dificuldade de escapar dela para projetar a compreensão de alteridade em nível teórico e, para além disso, acusar a sensibilidade dela na prática da sociabilidade diária. Ideologicamente, ainda não recusamos, nas atitudes, certas abstrações, construídas com base na categoria da identidade, conforme destaca Ponzio (2008, p.234):

\begin{abstract}
as abstrações concretas as quais constituem nossa Realidade: Indivíduo, Sociedade, Estado, Nação, Verdade, Saber, Igualdade, Justiça, Liberdade, Responsabilidade circunscrita e definida, Necessidade, Troca recíproca etc., abstrações concretas que vivem dentro do sistema global de reprodução social atual
\end{abstract}

A propósito, um exemplo é este recorte de Orlandi (2009, p.230) que selecionei por sua atitude "transgressora": "Eu, de minha parte, serei sempre pessimista enquanto a palavra 'democracia' surtir seu efeito mágico..."

Esse processo generalizado de identificação tem amplo alcance, levando à ideia de Universal, de processo único hoje atrelado à Produção, ao Mercado e ao Consumo como entidades legitimadas na globalização. O ideal talvez não seja construir identidades, mas desconstruí-las, porque hoje as identidades se tornaram assassinas. Daí o movimento crítico preconizado por Orlandi (2009) como 'desmundialização', como se verá na seção a seguir.

É justamente a crítica a esse regime, a essa Razão "que compreende as razões para eliminar, marginalizar, segregar, inclusive exterminar o outro" (PONZIO, 2008, p.235), que cabe levar a cabo para limpar o terreno para a pesquisa indisciplinar.

$\mathrm{Na}$ seção 2, para esse efeito, exponho algumas direções sugeridas por pesquisadores.

\title{
2 PESQUISAS INDISCIPLINARES (AGENDA QUEER?)
}

Se as pesquisas aplicadas em linguagem têm de pensar a língua como realidade vivida, uma consequência é sua abordagem transdisciplinar, como expõe e justifica Celani (cf. 1998, p.132-133), que parafraseio: uma visão transdisciplinar não supõe justaposição de saberes, mas interação, atravessamento de campos; trata-se, em correspondência à interação subjetiva, da interação de saberes. É o princípio do dialogismo que governa essa relação (de saberes e de sujeitos) - portanto, a heterogeneidade governa a prática e os modos específicos de conduzi-la.

Ao organizar a obra Por uma linguística aplicada indisciplinar, Moita Lopes (2006) aponta o lema Novos tempos, novas teorizações, investindo na necessidade de mudança de rumo da área, questionando as fronteiras e apostando na heresia de uma LA mestiça e ideológica. Ou seja, teoricamente, pelo cruzamento ou abandono de fronteiras disciplinares; na prática teórica (em movimento de vaivém), a vivência da infinidade de práticas sociais contemporâneas, à espera de novos olhares e novas atitudes. Chama-me a atenção, nessa proposta, este ponto assinalado por Moita Lopes (2006, p.27):

a possibilidade política de que a pesquisa contemple outras histórias sobre quem somos ou outras formas de sociabilidade que tragam para o centro de atenção vidas marginalizadas do ponto de vista dos atravessamentos identitários de classe social, raça, etnia, gênero, sexualidade, nacionalidade etc. 
As pesquisas queer, como já se tem chamado, são uma novidade, mas já têm os pés firmados, como as do evento chamado Queering Paradigms. Trata-se de um congresso que, em sua quarta edição, foi sediado pela Universidade Federal do Rio de Janeiro (UFRJ) e pela Universidade Federal do Estado do Rio de Janeiro (UNIRIO) em julho de 2012. Como se define o queer? Ali, a referência se faz "a um domínio indefinido e sem fronteiras de gêneros, sexualidades e práticas corporais não-normativas que inclui uma filiação a abordagens analíticas críticas". Deseja-se, portanto, desestabilizar o que está constituído em todos os setores da cultura, o que implica deslocar paradigmas totalizantes, aproximando campos consagrados como disciplinas.

Penso que a pesquisa queer seria algo como a "literatura da ciência" - o sair do lugar comum. De fato, encontro em Ponzio (2008, p.240) uma passagem sobre a escrita literária como prática cultural como em qualquer ciência (ela não teria um espaço circunscrito em sua reconhecida legitimidade):

A escrita literária permite entrever na linguagem a possibilidade de romper, desbaratar, colocar em discussão a ontologia, a totalidade, o ser, a narração. A escrita literária coloca em prática a possibilidade de uma nova razão, a possibilidade de uma dialética da razão dialógica.

Consultando o dicionário Exitus das línguas inglesa e portuguesa, v. 1 inglês-português (HOUAISS; AVERY, 1981), veremos, em síntese: Queer: esquisito, estranho, singular, bizarro. Também (coloq.) suspeito, duvidoso; também desequilibrado mentalmente; também (gíria) falsificado; homossexual; também verbo: atrapalhar, prejudicar. É, perceptivelmente, uma corrente de ressonâncias ideologicamente derivadas a partir de uma marca aparentemente neutra: "singular" que remete, portanto, a uma socialidade/discursividade legitimada, ponto de partida da consonância a uma vida social regularizada.

Ora, ao se dar espaço, tempo, voz e escuta a esses outros que são parte de nossa vivência, é/será possível entender melhor o mundo contemporâneo e, como especifica Moita Lopes, "colaborar na construção de uma agenda anti-hegemônica em um mundo globalizado, ao mesmo tempo em que redescreve a vida social e as formas de conhecêla" (2006, p.27). Nesse sentido, gostaria de lembrar um caso exemplar relatado por Orlandi (2009) numa abordagem discursiva, salientando sua relevância nos termos da LA aqui preconizada.

No trabalho a autora procura mostrar a relação entre o indivíduo e a sociedade em espaço urbano para estabelecer "a forma e a necessidade" de movimentos que acabam resultando na delinquência. Teoricamente, ela admite "a interpelação do indivíduo em sujeito (forma histórica do sujeito capitalista, sustentado pelo jurídico) e sua individuação pelo Estado, resultando daí um sujeito ao mesmo tempo livre e responsável." (2009, p.219). Essa relação é política, e tal constituição se perde no esquecimento, abrindo um mundo imaginário em que o consenso tem muito peso na organização das políticas públicas.

Orlandi associa o discurso da mundialização e as tecnologias da linguagem à superveniência da criminalidade, da delinquência, do terrorismo, apesar da tão propagada "democracia planetária". Nem o multiculturalismo, o multilinguismo, a biodiversidade e seus derivados (a inclusão, o assistencialismo) escondem que há uma formação ideológica capitalista dominante, e todas as discursividades aí agregadas têm, como aposta Orlandi, um mal de raiz: o preconceito, que é regido pelo poder econômico. 
A autora tem estudado a subjetividade resultante desse fenômeno no espaço urbano: "o sujeito do grafite, do piercing, da tatuagem e do rap, o menino do tráfíco (Falcões)" (2009, p.220), e observa que o preconceito se materializa, em sua forma radical, na negação da existência do "outro". ${ }^{2}$ Nessa direção, penso que a tolerância, que parece, em sua inocência verbal, ligada a uma virtude, no contexto apareceria apenas como uma atitude preconceituosa menos dramática que o ódio escancarado (intolerância). Pregar a tolerância (como se faz também no campo religioso, na forma do ecumenismo, em sua abertura para o universal ${ }^{3}$ ) tem sido uma forma de "civilizar" a humanidade, o que não elimina os sentimentos de desgosto relativamente a certas diferenças. Até o "inferno" deve ser tolerado ("O inferno são os outros", na reflexão de Sartre - mas esses outros, mesmo atrapalhando minha caminhada, são necessários para a compreensão de mim mesmo).

Pois bem, ao deixar-se envolver pelo mundo dos marginalizados, Orlandi olha concretamente o movimento desses corpos que perambulam e agem contra a ideologia oficial em espaços restritos, corpos que estão segregados, e entende que "segregado é aquele que não tem direito de existir. É o sujeito à extinção." (2009, p.227). O Estado falha em sua função de articulador do simbólico com o político. "Ao produzir o semsentido produz-se, com este, as condições da violência" (2009, p.228).

No final de seu texto, fazendo um comentário metodológico, Orlandi informa que propôs o termo 'descolonização' para falar de língua, de ciência. E agora, deseja a desmundialização:

desmundializar a reflexão, desmundializar o cientista significa nos confrontarmos política e simbolicamente com a materialidade da nossa história e de nossos sujeitos em seus processos de constituição, encontrando outros sentidos para a sociedade de modo a que os laços sociais sejam a nossa força, e não nos deixem dispersos, frágeis e sem referências. (ORLANDI, 2009, p.233)

Com base nesse exemplo, observa-se que o Estado não pode simplesmente esquecer esses sujeitos-corpos como não ser, pois suas atitudes forçam, de certa forma, a tomar uma atitude de contrarresposta, e esta se manifesta, no modo político da inclusão, como a tentativa de adaptá-los às regras do Estado, ou, no modo da exclusão, à segregação pura e simples ${ }^{4}$. Uma explicação para essa condição nos vem de Ponzio, ao

\footnotetext{
${ }^{2}$ Aceito, como pano de fundo, esta distinção apresentada por Leite $(2008$, p.20) ao tratar o preconceito e a intolerância na linguagem: "preconceito é a ideia, a opinião ou o sentimento que pode conduzir o indivíduo à intolerância"; esta, então, aparece como um comportamento, uma reação que pode ser agressiva e mesmo letal. Preconceito materializado, portanto. É sabido que o espectro semântico de tolerância/intolerância é bastante amplo e historicamente relativo, por isso destaco que focalizo o contexto específico desta reflexão.

${ }^{3}$ Ecumênico: gr. oikoumenikós, 'do ou aberto para o mundo inteiro' pelo lat. oecumenìcus, a,um 'universal, de todo orbe' (HOUAISS, 2001). Note-se a restrição neste contexto: num "concílio ecumênico", presidido pelo papa, são convocados todos os prelados católicos. Por analogia, sem o uso de 'concílio', há abertura quando se congregam pessoas de diferentes credos e ideologias (HOUAISS, 2001). Só aparentemente 'ecumênico' e 'católico' se superpõem.

${ }^{4}$ Inclusão pode ser apenas reflexo da intolerância, não manifestação empática de reconhecimento da existência e dignidade. Na expressão de Rouanet (2003), "a intolerância se caracteriza pela incapacidade de descentramento, de empatia com o ponto de vista do outro". E ainda: "a tolerância não pode ser a última palavra. A implantação de uma cultura da tolerância é um cessar-fogo na guerra das diferenças, mas ainda não é a paz. [...] É preciso passar de uma ética da tolerância, em que as diferenças coexistem, para uma ética do reconhecimento mútuo e da interpenetração."
} 
retomar Bakhtin e o dialogismo: o diálogo, em Bakhtin, não diz respeito a uma atitude aberta na relação com os outros (o que seria um entendimento errôneo da visão bakhtiniana), mas "consiste na impossibilidade - da ordem 'biossemiótica', podemos dizer, e não somente psicológica e cultural - de fechamento, de indiferença, de nãoenvolvimento." (PONZIO, 2008, p.290). De alguma forma, esse outro indisciplinado é uma ameaça ao espaço de uma identidade, em qualquer de suas formas, e produz um medo crescente "quanto maior for a exclusão do outro", observa Ponzio (2008, p.236). O limite superior do processo de exclusão, como sabemos, é a "decretação" da morte física - o que pode ocorrer por meios legais (pena de morte) ou dissimulados (assassinato).

Entretanto, continuamos a ser professores, e nossa agenda cotidiana registra o contato ininterrupto com nossos alunos, e o enlaçamento com todas as vidas que circulam nos espaços históricos da instituição, que se derramam para qualquer outro espaço físico em que estejamos relacionados a eles. É aí, na imediatez de interlocuções diárias, que estaremos amadurecendo em termos alteritários.

Vemos que as pesquisas indisciplinares e transdisciplinares, ampliando o leque de perspectivas de estudo na atualidade, têm um caráter abertamente político, e o político é a dimensão de cobertura para a compreensão de fenômenos que se interpenetram e se tornam campo privilegiado da LA. É aí que 'indisciplinar' adquire uma ressonância de movimento que foge à letargia dos sentidos que, via reprodução, se desfazem.

Por isso, após comentar uma passagem sobre "pedagogia crítica" (em Rajagopalan) e a aproximação da LA com essa vertente da pedagogia, passo às considerações sobre o desafio da alteridade na produção de saberes em nossos relacionamentos mais imediatos - extensíveis a quaisquer outros contextos de ensino e pesquisa.

\section{PEDAGOGIA CRÍTICA E LA}

A "pedagogia crítica" de que fala Rajagopalan (2003), a qual tem em Paulo Freire um mentor - no contexto escolar institucional e espraiando-se para todas as esferas sociais -, é "um autêntico espelho das contradições e tensões que marcam a realidade que se verifica fora da escola" (2003, p.105). Isso significa, para mim e para muitos profissionais, que ensinar não pode se resumir em estar nas salas de aula como um porta-voz, um delegado encarregado de expor e fazer aprender conteúdos; para ensinar é preciso estar aí como participante histórico e político da vida das pessoas, em interlocução com elas. Desse modo, não há como transitar neutramente para dentro ou para fora - estamos sempre no círculo social, ainda que entrincheirados. Isso expressa a ilusão da autonomia teórico/prático. Num sentido mais genérico, no contexto literário, o escritor Amilcar Neves (2011) assim se manifesta, em sua fina ironia, na crônica Altocontraste: "As coisas ficam bem mais simples se forem binárias: zero ou um, norte ou sul, direita ou esquerda, certo ou errado, verdade ou mentira.",

Se, como diz Rajagopalan (2003, p.106), destacando o preconceito contra a prática, a "área acadêmica que se convencionou chamar de 'linguística aplicada' tem

\footnotetext{
5 Rouanet (2004), em artigo publicado na Folha de S. Paulo, fez referência aos "terríveis simplificadores", a partir do historiador Jacob Burckhardt - do ponto de vista político-filosófico, remetendo ao confronto bem-mal. Os dois exemplos emblemáticos do século XX são Adolf Hitler e Josef Stálin.
} 
origens 'nobres' e se mantém distante das preocupações do dia a dia do mundo comum dos mortais", como subárea de eventual aplicação da disciplina teórica, não é seu destino a continuidade desse modo de ser, haja vista a quantidade de projetos imbuídos da necessidade de participar de "outras formas de sociabilidade" (como expressa Moita Lopes). Um indício relevante desse deslocamento se manifesta também, do ponto de vista de política editorial, no periódico Trabalhos em Linguística Aplicada, da Unicamp, que assim expressa, hoje, o percurso de sua história:

\begin{abstract}
os artigos permitem traçar um panorama histórico da Linguística Aplicada no Brasil, suas transformações e sua consolidação ao longo dos anos, passando de uma visão de aplicação de teorias linguísticas ao ensino-aprendizagem da língua materna e da língua estrangeira, para uma perspectiva interdisciplinar de análise de diferentes situações de interação social mediadas pela linguagem, incluindo aspectos teórico-práticos da tradução, questões de identidade, entre outros. $(<\mathrm{http}: / / \mathrm{www}$. scielo.br/revistas/tla/paboutj.htm $>)$
\end{abstract}

A distinção conhecimento teórico (técnico)/conhecimento prático, que presume a autonomia de cada lado, também tem sua filiação histórica, surgindo a teoria como uma arché: "A sociedade moderna, em nome da razão e do racionalismo inspirado na herança do Iluminismo, tem importante parcela de culpa ao enaltecer demasiadamente a razão técnica às custas da razão prática." (RAJAGOPALAN, 2003, p.109).

Para superar esse "alto-contraste", tal como expressa o escritor Amilcar Neves, vemos a proposta de Rajagopalan de "a linguística aplicada vir a se alinhar à pedagogia crítica" (109), e para abrir e alargar essa via será preciso "abrir mão de uma série de posicionamentos equivocados que ainda se acham incrustados no meio acadêmico" (109), tal como a separação entre trabalho pedagógico e questões políticas ${ }^{6}$. Nós fomos, gostemos ou não, "aculturados sob o regime da lógica binária, que é própria da metafísica do mundo ocidental", reconhece Rajagopalan. Entretanto, dada a característica da incompletude subjetiva e das mudanças perenes no mundo e nas linguagens que o representam e identificam, cabe deslocar essa lógica:

devemos saudar a tendência já emergente, embora ainda tímida, de repensar os termos em que foi feita a divisão do bolo entre a teoria e prática, entre reflexão e aplicação. A nova linguística aplicada que certamente surgirá das cinzas das práticas vigentes até há pouco conduzirá suas próprias reflexões teóricas, motivadas pelo critério de sua aplicabilidade como o mais importante de todos. (RAJAGOPALAN, 2006, p.80)

O que me toca especialmente nessas palavras é a abertura para a LA quanto à proposição de suas próprias reflexões teóricas, conduzidas pela emergência dos problemas sociais em meio a conflitos de toda ordem. E é nesse ponto que a transdisciplinaridade se legitima.

Se à LA, que ainda traz uma cicatriz do que teria sido sua vocação de origem, se faz outra de si mesma, cabe saudar a tendência (como expressa Rajagopalan) de se alinhar a uma pedagogia crítica, cruzando limites antes considerados naturais (naturalizados) em função de uma dicotomia que não oferece respostas ao mundo vivido. E no cerne dessa complexidade está a ética do relacionamento humano. Por isso,

6 A lista dos alto-contrastes poderia ser estendida: intelectual/manual; espiritual/corporal; dominador/dominado; civilizado/bárbaro, prosa/poesia... Hoje, porém, quando hesitamos entre essas taxonomias, sempre temos a possibilidade de indicar "outro" - o que é um sinal de abertura. 
como assinalei acima, retorno à pergunta de como poderíamos ser mediadores de saberes relativamente às formas de subjetividade em questão.

\section{EU, TU, ELE - E SEUS CONFLITOS}

Desejo salientar o papel fundamental da interlocução no processo de aproximação e distanciamento relativamente a sujeitos e os saberes correspondentes, apontando duas direções e seu entremeio: as relações eu/tu e eu-nós/ele, marcando a aproximação e o (possível) confronto (pesquisadores, professores, sujeitos afetados nas práticas de linguagem, especialmente no ensino, que é nossa prática mais tangível).

Trata-se de um tema que me tem ocupado nos últimos tempos ${ }^{7}$ e que procuro compreender perspectivando a mim mesma com um olhar exotópico (de distanciamento), visando a entrelaçar o estudo que dele faço com atitudes na vivência cotidiana, alimentando ou eventualmente deteriorando os saberes nessa experiência sem limites.

Ao propor em contraste as relações eu/tu e eu-nós/ele como formas pessoal e impessoal de comunicação discursiva, estou de fato marcando um mais e um menos, prevendo necessariamente o entremeio e suas variações, visto que não se trata de uma dicotomia, mas uma referência para compreender o processo. Utilizo aqui princípios e pressupostos da teoria sociointeracionista divulgados nos estudos do Círculo de Bakhtin. As relações interpessoais são, por princípio, marcadas pelo modo como interpretamos o mundo e nossos congêneres, individualmente ou em comunidades restritas ou amplas, prevendo a possibilidade de confronto de forças (mais ou menos aberto) - visto que não podemos desmanchar magicamente os níveis da hierarquia social - e a forma de equilibrá-las, bem como suas implicações no ensino e no aprendizado.

Retomo essas relações do modo como as explicitei em trabalho anterior.

1. em Bakhtin/Voloshinov (1979, p.101) encontramos uma forma de atividade mental orientada para "nós" - atividade mental do nós ${ }^{8}$-, que supõe desenvolvimento do grau de consciência, enriquecendo a atividade mental. Voltando-se para o outro, a relação eu/tu (sem presumir harmonia, concerto absoluto) representa também o reconhecimento desse outro e as possibilidades que ele abre para a maturação pessoal como capaz de, pela distância, oferecer algo que não temos ou vemos;

2. a relação eu-nós/ele, por sua vez, presume um afastamento; um sujeito se relaciona com um grupo mais fechado, sem que haja uma orientação social plena, visto que se trataria de atividade mental do eu, de um eu que se estende num círculo pequeno e individualista. Assim, apenas dentro desse círculo há o reconhecimento de iguais, em que "outros" estão em comunhão com cada "eu" desse círculo; porém, fora daí todos são "ele", ou seja, não são reconhecidos como "eu" pleno: são preferencialmente (em escala) estranhos, não amigos, não parceiros, segregáveis, inimigos (numa escala que pode ir da indiferença, passando pela tolerância, ao ódio aberto, embora variável relativamente ao tempo e às circunstâncias), representando algum grau de ameaça que desestabilizaria o grupo - ainda que entre os membros do grupo possa haver dissensões

\footnotetext{
${ }^{7}$ Em junho de 2011 apresentei um trabalho no I Simpósio de Estudos de Língua Portuguesa (SIELP), realizado na UFU (Uberlândia), tematizando a intersubjetividade relativamente ao tratamento dos conhecimentos na escola (FURLANETTO, 2011).

${ }^{8}$ A distinção aqui apresentada está baseada, porém de um modo livre, nos pressupostos sobre a atividade mental do eu e a atividade mental do nós exploradas na obra de Bakhtin/Voloshinov.
} 
a cada momento (como acontece em grupos aparentemente bem cimentados). Exemplos-limite desse caso são o que se denomina, nas sociedades supostamente bem ordenadas, seitas, facções, grupos fundamentalistas... - enfim, grupos já segregados em uma sociedade que organizam seu próprio estatuto de sobrevivência, e que estariam, aparentemente, apenas protegendo-se de um mundo ruim.

Bakhtin, ao estudar o corpo como valor, afirma: "A autopreservação é uma diretriz volitivo-emocional fria, totalmente desprovida de quaisquer elementos de amorcarinho e estética." (2003, p.45). Não estamos afirmando nem presumindo que isso seja exclusivo desses grupos, mas que o comportamento de estar sempre em guarda tem aí mais possibilidade de se imiscuir, deteriorando as relações humanas. Como, com sua indefectível complexidade, este se mostra um mundo desorganizado, indisciplinado, cria sujeitos, situações, lugares, relações que podem ser perspectivados como pontos de relevância social para a LA, como topicalizado antes.

Caberia, para os casos dos "fora-do-lugar", antes que pô-los no lugar com a utilização de dispositivos sociopolíticos; antes que julgá-los a partir das categorias disciplinares do correto/incorreto (ou legal/ilegal), confrontar-nos, como manifesta Orlandi (2009, p.233), "com a materialidade da nossa história e de nossos sujeitos em seus processos de constituição". Essa seria a forma primeira de indisciplina da LA uma indisciplina do caráter atravessador da linguagem nas ciências humanas, que aí estão para transacionar com ela: Filosofia, Antropologia, Etnologia, História, Educação, Psicologia, Psicanálise...

O contraste que assinalei nas duas categorias é, ressalto, uma referência; elas não estão em oposição para pessoas ou grupos específicos, mas se apresentam num continuum e não discriminam. Dadas as situações, os lugares e as pessoas, todos nós vivemos em tensão entre essas tendências, conscientemente ou não. Considero-as aqui importantes justamente porque é sempre por meio dos vínculos interpessoais que os saberes de que tratamos (especialmente os que circulam no meio escolar e acadêmico) são sentidos, avaliados e negociados. A pesquisa do meio social próximo e abrangente não exige menos que o trabalho pedagógico, nesse sentido.

Gostaria de introduzir neste espaço um tópico vinculado às relações interpessoais como vistas aqui, em dois recortes de textos "de vizinhos". Extrapolo, inicialmente, uma reflexão específica de Emmanuel Carneiro Leão, num estudo sobre mito e filosofia grega, mas apresentando o cotexto de sua discussão:

Uma leitura filosófica renuncia de bom grado a "explicar" o Mito. Espera
apenas preparar as condições para um encontro originário com seu advento.
Neste encontro a densidade da Linguagem mítica nos leva a superar o
desnível e a dualidade entre ouvido externo e ouvido interno, entre audição e
escuta. [...] Ler filosoficamente uma realização significa também acolher nas
peregrinações dos discursos a diferença entre língua e Linguagem. Significa
propiciar o diálogo entre a fala do Mito e a escuta do leitor a propósito da
realidade no advento de realizações históricas. (LEÃO, 1987, p.7, grifo meu)

É nesta distinção que quero me fixar, ainda que eu esteja fazendo deslizar sentidos: audição (ouvido externo) e escuta (ouvido interno). A mera audição pode resultar em indiferença; a escuta faz ressoar, está ligada ao diálogo e à história.

O outro recorte vem da área de Comunicação, de uma coletânea já clássica de Hayakawa (1977), onde se encontra o texto (dele mesmo) Como assistir a uma conferência. Ele focaliza aí um aspecto da comunicação que ele considerava 
negligenciado: "como escutar devidamente". Quero destacar as passagens mais marcadas a respeito disso:

\begin{abstract}
poucas pessoas, além dos psiquiatras e mulheres, tiveram treino suficiente em saber escutar. [...] é necessário enfatizar que escutar não significa simplesmente manter um silêncio polido, enquanto no foro íntimo, você ensaia o que irá dizer assim que tiver a oportunidade de iniciar um assunto. Escutar também não significa ficar de tocaia, atento às falhas na argumentação do parceiro, de modo que mais adiante você possa derrubá-lo. Escutar significa visualizar o problema do mesmo modo que o emissor - o que não significa simpatia, isto é sentir pelo outro, mas empatia, isto é, vivenciar com o outro. Escutar requer um engajamento ativo e com imaginação na situação do parceiro e um esforço para entender um marco de referência diferente do nosso. Nem sempre isto constitui tarefa amena. (HAYAKAWA, 1977, p.68-69, grifos do autor)
\end{abstract}

Como se percebe, trata-se, nos dois casos, de um trabalho de aproximação da relação interpessoal eu-tu, que visa ao desenvolvimento do grau de consciência, da ética no relacionamento humano. Não é, de fato, uma tarefa amena.

O inacabamento na constituição da subjetividade e o papel do conhecimento no plano da existência cobram de nós o reconhecimento do outro como capaz de completar nosso horizonte, ao mesmo tempo devendo-se garantir a originalidade de cada um. Trata-se, como diz Bakhtin, de entrar em empatia, tentar entender axiologicamente o mundo como o outro o vê, pôr-se em seu lugar para avaliar, depois, o modo de completar seu horizonte com o excedente de visão que de outro lugar é possível ter dele (v. BAKHTIN, 2003, p.23). Esta é uma lição difícil que nos cabe praticar, sem a qual estaremos sempre distanciados daqueles que será preciso atender.

Tendo encontrado, em situação acadêmica específica, um texto que qualifico como emblemático do tema discutido aqui, permito-me anexá-lo para reflexão pelos leitores.

\title{
5 FINALIZANDO
}

No contexto da atitude indisciplinar preconizada para a teorização de linguagem amparada pelas práticas de todos os matizes nas esferas sociais, compondo o espaço transdisciplinar da LA, tematizei a relação eu/tu em contraste (mas formando um contínuo matizado) com a que objetifica o ele - quando um grupo atua de maneira exclusiva $^{9}$, ou apenas manifestando uma individualidade pouco porosa em situações específicas, desde a indiferença até a repulsa -, vendo essa relação como uma questão ética. O exercício do encontro empático com o outro em meio aos desencontros e conflitos, em qualquer esfera, parece-me de importância crucial. Como há sempre um antes e um depois, pensei numa dupla vetorialidade:

1. para um passado fluindo para o agora, na forma de atitudes e percepções relativamente a conhecimentos disponíveis para uma formação específica; trata-se, aqui, de nossa visada para os outros que compõem nossa memória de arquivo, mas que não desejamos apenas reproduzir, e sim compreender e avaliar;

\footnotetext{
${ }^{9}$ Aqui, o termo 'exclusivo' indica um agrupamento mais fechado, com regras e valores estabelecidos para seu próprio relacionamento e em função do mundo "lá fora", um outro que é preciso considerar com certos cuidados.
} 
2. para um agora que flui continuamente para diante (tornando-se memória do presente), endereçado àqueles pelos quais somos diretamente ou indiretamente responsáveis, em situações e momentos específicos, pelo reconhecimento da alteridade nas pessoas singulares, pela escuta, pela não indiferença. "As complexas relações de reciprocidade com a palavra do outro em todos os campos da cultura e da atividade completam toda a vida do homem." (BAKHTIN, 2003, p.379).

Ao fechar esta reflexão sobre a ética de nossas atividades, como professores e pesquisadores, complemento-a com a ênfase feita por Rojo (2006, p.273) sobre a necessidade de a LA contemporânea assumir

configurações teórico-metodológicas próprias, autônomas não só da linguística inaugural, mas também das outras disciplinas de referência [...], porque rearticuladas de um ponto de vista "próprio", colocado pelo problema a resolver.

Ou seja, o ponto de vista próprio é exigido pela especificidade das situações, dos sujeitos e dos objetivos - o que nos obriga a (re)considerar uma miríade de condições e significações de que depende uma atuação efetivamente interativa, voltada às respostas adequadas a cada problema e conflito. Assim, criando um espaço próprio e modos de conduzir as questões, bem como formas não estáveis de tratar cada prática em seu tempo, espaço e condição política dos sujeitos, rearticulando a riqueza dos conhecimentos indispensáveis à sua própria condição de campo transdisciplinar, a LA pode fazer-se e refazer-se sem limites.

\section{REFERÊNCIAS BIBLIOGRÁFICAS}

BAKHTIN, M. (VOLOSHINOV). Marxismo e filosofia da linguagem. Tradução de Michel Lahud e Yara Frateschi Vieira. São Paulo: Hucitec, 1979.

Estética da criação verbal. Tradução do russo por Paulo Bezerra. São Paulo: Martins Fontes, 2003.

CELANI, M. A. A. Transdisciplinaridade na Linguística Aplicada no Brasil. In:

SIGNORINI, I.; CAVALCANTI, M. C. (Orgs.). Linguística Aplicada e transdisciplinaridade. Campinas: Mercado de Letras, 1998. p. 129-142.

ESTEVES, P. F. Eu nomeio-te, ele indigna-se. Jornal de Negócios, Lisboa, 16 jan. 2012. Caderno Opinião. Disponível em: $<$ http://www.jornaldenegocios.pt/home.php?template=SHOWNEWS_V2\&id=531889>. Acesso em: 19 fev. 2012.

FARACO, C. A. Pesquisa aplicada em linguagem: alguns desafios para o novo milênio. D.E.L.T.A., v. 17, n. especial, p. 1-9, 2001.

FURLANETTO, M. M. Os gêneros do discurso na esfera escolar: relações interpessoais e conhecimento para a/na prática. In: SIMPÓSIO INTERNACIONAL DE ENSINO DE LÍNGUA PORTUGUESA. 1., 2011. Anais do... Uberlândia: Universidade Federal de Uberlândia, 2011. Disponível em: 
$<$ http://www.ileel.ufu.br/anaisdosielp/pt/arquivos/sielp2011/artigo_72.pdf $>$. Acesso em: 20 jan. 2012.

HAYAKAWA, S.I. Como assistir a uma conferência. In: (Org.). Uso e mau uso da linguagem. São Paulo: Pioneira, 1977. p. 65-71.

HOUAISS, A.; AVERY, C. B. (Eds.). Dicionário Exitus das línguas inglesa e portuguesa. Vol. 1: inglês-português. Englewood Cliffs, New Jersey: Prentice-Hall, Inc., 1981.

HOUAISS, A. Dicionário eletrônico Houaiss da língua portuguesa. Rio de Janeiro: Editora Objetiva Ltda., 2001.

LEÃO, E. C. Mito e filosofia grega. Tempo Brasileiro, Rio de Janeiro, v. 91, p. 5-9, out./dez. 1987.

LEITE, M. Q. Preconceito e intolerância na linguagem. São Paulo: Contexto, 2008.

MOITA LOPES, L. P. da. Uma linguística aplicada mestiça e ideológica: Interrogando o campo como linguista aplicado. In: indisciplinar. São Paulo: Parábola, 2006. p. 13-44. (Org.). Por uma linguística aplicada

NEVES, A. “Alto-contraste”. Crônica. Diário Catarinense, Florianópolis, 21 set. 2011. Disponível em: <http://www.recantodasletras.com.br/cronicas/3231667> . Acesso em: 21 set. 2011.

ORLANDI, E. P. Espaço da violência: o sentido da delinquência. Cadernos de Estudos Linguísticos, v. 51, n. 2, p. 219-234, jul./dez. 2009.

PONZIO, A. A revolução bakhtiniana. O pensamento de Bakhtin e a ideologia contemporânea. São Paulo: Contexto, 2008.

RAJAGOPALAN, K. Por uma linguística crítica: linguagem, identidade e a questão ética. São Paulo: Parábola, 2003. p. 37-48.

ROJO, R. H. R. Fazer linguística aplicada em perspectiva sócio-histórica: privação sofrida e leveza de pensamento. In: MOITA LOPES, L. P. (Org.). Por uma linguística aplicada indisciplinar. São Paulo: Parábola, 2006. p. 253-276.

ROUANET, S. P. O eros das diferenças. Revista Espaço Acadêmico, n. 22, mar. 2003. Disponível em: <http://www.espacoacademico.com.br/022/22crouanet.htm>. Acesso em: 28 set. 2011.

Os terríveis simplificadores. Folha de S. Paulo, São Paulo, 4 jan. 2014.

Caderno Mais. Disponível em: $<\mathrm{http}: / / \mathrm{www}$.academia.org.br/>. Acesso em: 28 set. 2011. 


\section{ANEXO}

Eu nomeio-te, ele indigna-se

Pedro Ferreira Esteves (16-01-2012)

$\mathrm{Eu}$, tu e ele. Eu nomeio, tu és nomeado e ele indigna-se. Eu sou ministro, tu és gestor e ele é contribuinte. Eu sou secretário de Estado, tu és meu ex-colega e ele é eleitor. Eu conheço-te, tu conheces-me e ele não conhece ninguém

As decisões em Portugal tomam-se com pronomes, são um processo de selecção. Uma selecção dos mais fortes, dos que chegam mais longe, dos que chegam mais alto. Eu e tu decidimos e ele não. Eu e tu sabemos e ele não sabe nada. E quando ele souber, eu e tu já sabemos mais.

Eu sou presidente, tu és primeiro-ministro e ele elegeu-nos. Eu sou deputado, tu és deputado e ele está na galeria. Eu sou CEO, tu és um grande accionista e ele é um pequeno accionista. Eu sou regulador, tu és operador e ele é cliente. Eu sou juiz, tu és advogado e ele é suspeito.

Eu sou maçon, tu estás de avental e ele nem sonha. Eu vou para a Holanda, tu escolhes Caimão, ele paga no Terreiro do Paço. Eu decido, tu concordas e ele vai discordar. Mas ele não nos toca. Ele reclama, ele resigna-se, ele raramente protesta, ele não é violento, há uma tradição neste País que ele respeita. Que nos respeita. Eu tenho direito, tu tens direito e ele tem direito à indignação. Somos um País livre. Eu posso, tu mandas e ele obedece. Eu sonho, tu queres e ele faz. Eu crio emprego, tu dás emprego e ele está desempregado. Eu pago porque tenho, tu pagas porque podes e ele paga o que pode. Quando pode.

Os pronomes do poder em Portugal raramente têm plural. Nós, no poder, é um plural singular. Nós somos eu e tu. Nós não somos eu, tu e ele. Vós, é Vossa Excelência. És tu, mas com deferência. Eles. Eles são eles, é ele com outros como ele. Eles não sabem, Nós sabemos.

Nós nacionalizamos e eles pagam. Nós privatizamos e eles pagam. Nós concessionamos e eles pagam. Nós nomeamos e eles nunca são nomeados. Nós entramos em tribunal como arguidos e eles saem como acusados. Nós defendemo-nos e eles nem sequer atacam.

As elites do poder em Portugal têm um problema fundamental. Não compreendem, ou não querem compreender, a sua utilidade pública. Recusam-na, num momento em que o poder que acumularam devia servir a todos. Para servir todos. A tragédia é que, no labirinto em que o País se encontra, a saída de emergência mais perto está bloqueada. E não passam todos na porta. Passa quem pode, passa quem sabe, não passa quem quer e muito menos quem precisa.

Nós passamos, eu escolho-te, tu segues-me e passamos. Eles não passam.

Editor de Empresas

Visto por dentro é um espaço de opinião de jornalistas do Negócios

$<$ http://www.jornaldenegocios.pt/home.php?template=SHOWNEWS_V2\&id=531889>

Recebido em: 10 de outubro de 2013.

Aprovado em: 11 de abril de 2014. 